Article

\title{
Assessing Tourists' Preferences of Negative Externalities of Environmental Management Programs: A Case Study on Invasive Species in Shei-Pa National Park, Taiwan
}

\author{
Tzu-Ming Liu ${ }^{1, *(1)}$ and Chia-Mei Tien ${ }^{2}$ \\ 1 Graduate Institute of Marine Affairs, National Sun Yat-sen University, Kaohsiung 80424, Taiwan \\ 2 Marketing and Sales Department, Queena Plaza Hotel Tainan, Tainan 71081, Taiwan; clara@queenaplaza.com \\ * Correspondence: liutm.tw@gmail.com
}

Received: 9 May 2019; Accepted: 20 May 2019; Published: 24 May 2019

check for updates

\begin{abstract}
This study uses discrete choice experiments to evaluate and reduce the environmental impact of negative externalities of managing invasive alien species (IAS), such as "ecological shock", "health risk", "waiting time" "tour range" and "prevention and control fee", on the support of IAS prevention and control. We used data from Taiwan's Shei-Pa National Park and its visitors for the case study and obtained 602 valid questionnaires. The results indicate that visitors consider that each unit of externality of IAS prevention and control measures significantly reduces their utility, and the magnitude equals the estimated value of externality. However, although negative externalities are inevitable, the support for IAS prevention and control measures could be maximized by adjusting the types and proportions of negative externalities. For example, visitors are willing to sacrifice up to $1.41 \%$ of the tour range in exchange for a $1 \%$ reduction in ecological shock. This study summarizes the negative externalities of IAS prevention and control measures and proposes to adjust the combination of negative externalities to reduce the shocks of those IAS prevention and control measures on the public, so as to increase the public support for IAS policies and increase the sustainability of tourism.
\end{abstract}

Keywords: discrete choice experiments; invasive species control; tourists' preferences; two stage on-site sampling; negative externalities

\section{Introduction}

National parks (NPs) not only bear the important responsibility of protecting key eco-environments and landscapes but also must meet the needs of public sightseeing and recreation. The various sustainability objectives of NPs are occasionally compatible but may also conflict with one another [1]. Such conflicts are particularly obvious in the prevention and control of invasive alien species (IASs). Because IASs can spread by attaching themselves to the human body, clothing, vehicles, and recreational equipment, the greater that the number of tourists who visit NPs is, the greater the probability that the NPs will be impacted and the higher the severity of the impact [2-6]. Once it enters an NP, an IAS may change the characteristics of the park ecosystem, compete with local species for food, cause local species to disappear, and change the landscape. This problem worsens with the increase in the number of NP tourists. IAS prevention and control is therefore regarded as the largest challenge facing NP management $[7,8]$.

The impact of IASs on sustainability of NPs has been documented. For example, the cinnamon fungus caused a large area of forest blight in Brisbane Ranges NP in Australia and a decrease in its vegetation coverage rate [9]. The mile-a-minute weed reduced the plant richness of the Chitwan NP in Nepal [10]. The Burmese python caused a significant reduction in the number of mammals and birds 
in Everglades NP [11]. IASs not only severely damage the ecology and landscape of NPs, they also harm other IASs. For example, in America's Hawaii Volcanoes National Park, the firebush gradually replaced the endemic plant ohia [12] while promoting the expansion of the leafhopper population, another IAS [13], and the subsequent apoptosis of native plants. These cases show that IASs pose a serious threat to the precious biodiversity of NPs and change the original landscape. Therefore, many NPs seek to actively controlled and manage IASs $[14,15]$. However, these NPs often find themselves in a unique dilemma in regard to preventing and controlling IASs.

The first challenge to NPs in the prevention and control of IASs is that the prevention and control measures often endanger other species and the ecology in NPs. The Booderee NP's approach to controlling the bitou bush reduced the number of bird species in the park [16]. Capitol Reef NP's efforts to control the codling moth also reduced alfalfa leafcutting bee's nectar, which in turn threatened several species of endangered plants in the park [17]. Measures taken by Queensland Conservation Reserve to control para grass resulted in a decrease in the abundance of amphibians and reptiles, such as skinks and frogs, in the park [18]. Antioch Dunes National Wildlife Refuge applied chemical agents to inhibit ripgut brome only to drastically reduce the hatchability of Lange's metalmark butterfly, an internationally endangered species [19]. Therefore, in preventing and controlling IASs, NPs must understand potential side effects (i.e., negative externalities) and choose the most appropriate approach [18].

Sightseeing and recreational activities are another challenge to NPs in preventing and controlling IASs. This challenge originates in the fact that tourists are a medium of IAS proliferation. Thus, IAS prevention measures can impinge on tourist sightseeing and recreation activities. Therefore, NP business management confronts conflicting objectives: providing sightseeing opportunities and preventing IAS proliferation. Many studies confirm that tourists contribute to IAS proliferation. Lonsdale and Lane [20] investigated IASs attached to tourist vehicles in Kakadu NP. They collected 1960 seeds from 304 vehicles and found that one vehicle alone carried 789 seeds belonging to 15 plants. Research by Whinam, et al. [21] on tourists at the Macquarie Island Nature Reserve produced similar findings. An investigation of the clothing, belongings, and travel equipment of 64 visitors found 981 seeds belonging to 15 families and 90 plants. The cited studies confirm that tourists are a medium by which IASs enter NPs. Therefore, the more tourists that there are, the higher the risk of NPs being impacted by IASs. In terms of managing the IAS impact, NPs face two conflicting management objectives: reducing IAS risk and maintaining normal sightseeing and recreational activities.

Preventing and controlling IASs can negatively impact tourists in many ways. For example, the ecological impact of IAS prevention and control can reduce the quality of tourist recreation [22]. Chemicals used to prevent and control IASs are harmful to tourist health [23]. Closing controlled areas reduces the available recreational area. An IAS inspection prior to entrance into the park delays tourists. All these examples represent negative externalities of IAS prevention and control. Such externalities decrease tourist recreational satisfaction with NPs, which pressures NPs managers to adopt corrective measures [24,25]. However, if an NP repeatedly modifies its IAS prevention and control strategy in response to tourist complaints, it may compromise the efficiency of the strategy and aggravate the IAS problem. Therefore, when planning measures to prevent and control IASs, NPs must carefully consider any negative externalities and tourist comments on such externalities. Currently, there is a lack of research on the preferences of NPs tourists regarding the negative externalities associated with IAS prevention and control. A detailed analysis of NP tourist preferences regarding the negative externalities of NP IAS prevention and control would help NPs evaluate tourist responses to the trade-offs between the externalities and the tourists' willing-to-pay price. Then, based on the trade-offs and the willing-to-pay price, prevention and control measures could be designed that have the least impact on tourists (which represents the tourists' first preference). With the help of such an analysis, NPs could avoid the conflict between tourist recreational demands and IAS prevention and control.

To close the previously noted research gap, this study investigates the trade-offs between NP tourists and the externalities of IAS prevention and control measures. Taiwan's Shei-Pa National 
Park is chosen as the research focus. The following section explains the measures adopted to prevent and control IASs and generalizes the externalities of the measures for use in an attributes-of-choice experiment. This study's most important contribution is its focus on the negative externalities of IAS prevention and control measures. The results of this study reflect our effort to consider both the need for NPs to prevent and control IASs and their dependence of the support of NP tourists.

\section{Overview of Shei-Pa NP, Taiwan}

Shei-Pa NP is a mountain-type NP features glacial landforms, ice-age relict species, unique landscapes and aboriginal culture. There is an ice-age relict species called the Formosan land-locked salmon (Oncorhynchus masou formosanus), an endemic subspecies of Taiwan, which proves the impacts of the glaciation process and the uplifting of mountain ranges on Taiwan. It is a miraculous and major discovery of biogeography. The main peak of Snow Mountain, a height of $3886 \mathrm{~m}$, is the highest point in the NP and the second-highest peak in Taiwan. Mount Dabajian, $3492 \mathrm{~m}$ above sea level, has a sharp and steep shape and is surrounded by rugged terrain and cliffs. It is the core area of the Atayal native tribe and the birthplace of the ancestors of the Saisiyat native tribe. Those fragile and rare ecological and cultural features of Shei-Pa NP attract a large number of visitors. How to balance conservation demands and recreational impacts is a major challenge in the management of Shei-Pa NP, and the IAS issue is a top priority.

The management office of the Shei-Pa NP once investigated the IAS in the park. The research found a total of 65 species of invasive plants, which could be categorized into 21 families and 48 genera, accounting for about a quarter of invasive plants in Taiwan. In terms of the proportion of IAS to native plants of Taiwan, the percentage for Shei-Pa NP was 20\%, much higher than the $6 \%$ for the rest of Taiwan. As visitors and hikers come and go, these IAS plants are likely to invade precious and rare habitats. For example, IAS plants have already spread to the Formosan land-locked salmon's habitat, where they have become dominant plants, which could impact the recovery of this endangered species. Exotic wildcats in the area prey on the protected green-backed tit (Parus monticolus), plumbeous water redstart (Phoenicurus fuliginosus) and Formosan shrew (Episoriculus fumidus). The exotic red-billed blue magpie (Urocissa erythrorhyncha) is observed to nest and feed together with the blue magpie (Urocissa caerulea), an endemic species in Taiwan. This behavior indicates that the two might hybridize, causing genetic pollution problems. These phenomena reflect the problem that IAS are invading Shei-Pa NP, which should be taken seriously.

\section{Data and Methodology}

\subsection{Negative Externalities of IAS Prevention and Control Measures and Questionnaire Design, Attributes and Levels}

To study the public preference for negative externalities of IAS prevention and control using the choice experiment method, the first step is to develop the attributes and levels of the questionnaires. In terms of the topic of negative externalities of IAS prevention and control, items to be considered include the target species to be prevented and controlled, control methods applicable to the target species, the characteristics of the ecosystem of the target species, cost, side effects and so on. The actual prevention and control plan is the result of multi-party assessment and is highly professional and technical. As far as surveys for public opinions are concerned, such information must be presented. However, it is impossible to present all the information combinations in the questionnaires. Moreover, the public likely cannot fully understand professional and technical information. Information combination, along with professional and technical issues, pose the most difficult obstacles to this research.

Professional and technical information should be assessed by professionals, but the opinions of the public should not be neglected. Therefore, we rely on both literature review and focus groups to arrive at a solution. We arranged three focus group discussions. Each time, there were six people, of whom two are IAS prevention and control professionals and the other four are not. With reference to 
the IUCN's top 100 IAS directory, we collect and summarize the target species, control and prevention methods applicable to target species, characteristics of the ecosystem of the target species, cost, and side effects as materials for the discussion of focus groups. The conclusions of the focus groups include the following: (1) conducting research on each target species one by one is too slow and not affordable; (2) the prevention and control measures are highly professional and technical, making them difficult for the public to understand, and they should be evaluated and planned by professionals; and (3) what the public is concerned about is the impact of those prevention and control measures. It is therefore recommended to assess the externalities of the control and prevention measures, rather than evaluating specific target species (e.g., RIFA) or specific methods of control (e.g., pesticides).

Based on the results of the focus groups and literature review, and considering the characteristics of the Shei-Pa NP, we summarize four negative externalities (or the so-called attributes in the choice experiment method) of the IAS prevention and control measures for visitors of NPs, including "the intensity of the impact of the prevention and control on the ecosystem", "recreational or visiting range reduced by those measures", "the possibility that visitors' health is negatively affected by the measures", and "waiting time of visitors caused by the implementation of the measures". We also determine the intensity of the four externalities (the so-called levels in the choice experiment method). Below are the explanations of the content and meaning of those attributes and levels.

1. The intensity of the impact of the prevention and control on the ecosystem (ecological shocks)

Biodiversity is an important factor that attracts visitors to NPs [22]. However, IAS prevention and control measures could cause serious negative impacts on the biodiversity of the treated areas, therefore reducing the utility of visitors in recreational activities. For a sense of the impact of IAS prevention and control measures on NPs' ecosystem, see the case studies of Booderee NP [16], Capitol Reef NP [17], the Queensland conservation reserve [18], and the Antioch Dunes National Wildlife Refuge [19]. Among those, Stark et al. (2012) estimated that the impact of IAS measures on the number of affected groups reached 30\%. According to the research of Stark, et al. [19], and based on the suggestion of Ryan, et al. [26] that each level of the attribute should be 15\% higher or lower than the baseline value or the previous level, we divide the intensity of the impact of the prevention and control on ecosystem to five levels at $0 \%, 15 \%, 30 \%, 45 \%$, and $60 \%$.

2. Recreational or visiting range reduced by those measures (tour range)

IAS prevention and control measures would affect the range of visitors' activities. For example, after applying chemicals in the IAS prevention areas, the areas would be closed to prevent visitors from coming into contact with those chemicals. When using manual labor and chain saws, the affected areas should be closed for the work. Tourist activities are often prohibited around the monitored facilities to avoid interference. However, there might be antagonism toward partial closure of some NP areas [27]. Therefore, limitation of the scope of visitors' recreational activities caused by the implementation of the prevention and control measure of IAS is also one of the externalities of those measures. This attribute is expressed as the percentage of reduced recreational or visiting range and is set at $0 \%, 20 \%, 40 \%, 60 \%$ and $80 \%$.

3. The possibility that visitors' health is negatively affected by the measures (health risk)

IAS prevention and control measures include the use of chemicals, but chemical agents could affect human health and cause diseases [23]. Using chemical methods for prevention and control in recreational areas might affect the health of visitors, which is one of the negative externalities of prevention and control measures. Currently, there is no relevant literature that provides specific and empirical data on the level of negative impacts of IAS chemical prevention and control on visitors' health. We assume probability values of each level at $0 \%, 30 \%, 60 \%$ and $90 \%$.

4. Waiting time of visitors caused by the implementation of the measures (waiting time) 
Because visitors cherish travel time [28], delay or waiting time would reduce their utility. Therefore, when the implementation of IAS prevention and control measures in NPs causes delay, it becomes an externality of IAS prevention and control measures. According to LeDoux and Martin [29], those measures would cost each visitor approximately $15-20 \mathrm{~min}$. This research sets the attribute of levels of visitors' waiting time at $0,20,40$ and $60 \mathrm{~min}$.

To assess the willingness to pay for the various attributes of the externalities of the IAS prevention and control measures, we establish the attribute of "additional and special fee for prevention and control collected at the entrance of attractions or parks".

5. Additional and special fee for prevention and control collected at the entrance of attractions or parks (prevention and control fee)

Based on the research of Adams, et al. [30] on Florida residents' willingness to pay for access to state parks, the fee levels are set at 40 NTD, 80 NTD, 120 NTD, 160 NTD, and 200 NTD, with a 120 NTD baseline.

After determining the attributes and levels, we use the orthogonal design methods to generate alternatives and obtain a total of 25 alternatives. Then, we divide these 25 alternatives into groups of 5 , and each group is called a scenario. Furthermore, to avoid the condition in which none of the 5 alternatives are accepted by respondents but they are required to make a choice, we add a "status $q u o^{\prime \prime}$ option to each scenario [31]. Thus, each questionnaire has 5 scenarios and each scenario has 6 alternatives.

\subsection{Econometrics Analysis}

We use the random utility maximization model to analyze the data. In this model, the utility of respondent when choosing alternative $i$ could be represented by the following formula:

$$
U_{i n}=V_{i n}+\varepsilon_{i n}, \forall i \in \mathrm{C}_{n}
$$

$U_{i n}$ is the utility of respondent $n$ with alternative $i$, and $C_{n}$ is the set of all available choices to respondent $n$. Because actual utility of the respondent could not be observed, we use $V_{\text {in }}$ to represent observable items and a random variable $\varepsilon_{\text {in }}$ for unobservable items. If $\varepsilon_{\text {in }}$ is i.i.d. with type 1 extreme value distribution (i.e., McFadden's conditional logit model), the probability of respondent $n$ choosing alternative $i$ could be represented by Formula (2):

$$
P_{\text {in }}=\frac{\exp \left(\mu V_{\text {in }}\right)}{\sum_{j \in \mathrm{C}} \exp \left(\mu V_{j n}\right)}
$$

In addition, we establish the linear function with the attribute of $V_{\text {in }}$ as in Formula (3):

$$
V_{\text {in }}=A S C_{i}+\beta_{1} X_{i 1} \ldots+\beta_{K} X_{i K}
$$

$\beta_{K}$ is the coefficient of attribute $K . X_{i K}$ represents attribute $K$ of alternative $i$ chosen by the respondent. Alternative-specific constant (ASC) is an indicator variable, showing whether the corresponding option is selected or not. Its estimated value shows the function that other attributes could not represent or the utility of the "status quo" [32]. If ASC is positive, it means that respondent prefers "status quo" to any other alternatives. Choosing another alternative would lower utility; therefore, the respondent chooses "status quo" and vice versa.

With the above assumptions, the marginal rate of substitution of each pair of attributes is represented by Formula (4):

$$
\mathrm{MRS}_{S K}=-\frac{\beta_{K}}{\beta_{S}}
$$

If the price attribute is $\beta_{S}$, the estimation of Formula (4) is the willingness to pay for $\beta_{K}$. 
This research conducted a questionnaire survey in Shei-Pa NP from March to November 2014. We used two-stage sampling to select the time and respondents of the survey. First, a stratified random sampling method was used to choose the survey time, and then, the systematic sampling method was used to obtain the samples. In this research, 4 survey months were randomly selected out of 12, specifically, March, July, August, and November. Then, the date of the survey was randomly selected for each month. On the day of the survey, we selected a number, sorted as the date of the day, between 0 and 9, from the random number table. On the same day, the visitor who passed the questionnaire distribution point in the order of the selected number became the first respondent. After that, three was used as the sampling unit, i.e., every third person who passed the questionnaire distribution point would be the next respondent. By randomly selecting the survey time and the initial respondent, we obtained the samples required by random sampling. A total of 692 people were surveyed, and 81 refused, making the rate of rejection $8.54 \%$. In the end, a total of 611 questionnaires were recovered. Among them, 9 were invalid, and 602 were valid, making the effective return ratio $98.5 \%$. Each respondent was required to answer questions regarding 5 scenarios. However, some of them did not complete all the scenarios, reducing the number of analyzable scenarios to 2998.

\section{Results}

The estimates of all attribute parameters are negative and statistically significant (Table 1), indicating that visitors believe that the externalities of IAS prevention and control measures significantly reduce their utility. The more the utility falls, the more difficult it is for the corresponding IAS prevention and control measure to get visitors' support. Using Formula (4), we calculate the willingness to pay of visitors for the negative externalities of IAS prevention and control measures (Table 1). The least preferred side effects are "ecological shock", followed by "health risk", "waiting time", and "tour range", and the last is the "prevention and control fee". These results reveal that the antipathy caused per unit of "ecological shock" is higher than that for any other types of externalities per unit. The utility of "none of the above" is -1.8732 , indicating that visitors believe that the utility of IAS prevention and control is higher than not having such prevention and control. These results respond to research purposes (1) and (4). Specifically, the public's willingness to pay for the IAS prevention and control measures is positive. Negative externalities of IAS prevention and control reduce the welfare of the public and reduce the support for IAS prevention and control measures. However, the proportion of various negative externalities could be adjusted following the results related to research purposes (2) and (3). Although negative externalities are unavoidable, visitors' support of IAS prevention and control measures could still be maximized.

MWTP was calculated based on parameter estimates of Equation (4).

Detailed parameter estimates of various externalities and willingness to pay are as below. "Ecological shock" is estimated to be -0.014 , indicating that it would reduce visitors' utility. Conversely, when ecological shock declines by $1 \%$, visitors' welfare would increase by 9.3 NTD. In other words, visitors are willing to pay 9.3 NTD to reduce $1 \%$ of ecological shock. "Tour range" is -0.0099 , showing that reduced visiting range would lower visitors' utility. In terms of willingness to pay, a $1 \%$ reduction of visiting range caused by prevention and control equals an increase in visitors' welfare of 6.6 NTD. The estimate for "health risk" is -0.0109 , indicating that the impact of prevention and control on the health of visitors would reduce their utility. A decline of $1 \%$ of health risk from prevention and control would increase visitors' welfare by 7.3 NTD. The value for waiting time is -0.0107 , meaning that waiting would reduce visitors' utility. Saving $1 \mathrm{~min}$ of waiting time could increase visitors' welfare by 7.1 NTD. The estimate for "prevention and control fee" is -0.0015 , which is smaller than those of other attributes and indicates that visitors are less inclined to other negative externalities caused by IAS prevention and control and are willing to pay to reduce these negative externalities. 
Table 1. Estimation results.

\begin{tabular}{|c|c|c|}
\hline Attributes & Coefficient & MWTP \\
\hline ASC & $\begin{array}{c}-1.8732^{* * *} \\
0.0846\end{array}$ & \\
\hline Ecological Shocks & $\begin{array}{c}-0.014^{* * *} \\
0.00107\end{array}$ & -9.3 \\
\hline Tour Range & $\begin{array}{c}-0.0099 * * \\
0.00082\end{array}$ & -6.6 \\
\hline Health Risk & $\begin{array}{c}-0.0109 * * * \\
0.0007\end{array}$ & -7.3 \\
\hline Waiting Time & $\begin{array}{c}-0.0107^{* *} \\
0.00104\end{array}$ & -7.1 \\
\hline Prevention and Control Fee & $\begin{array}{c}-0.0015 \text { * } \\
0.0004\end{array}$ & \\
\hline Observations & 2998 & \\
\hline Log-Likelihood & -5034 & \\
\hline $\mathrm{AIC}$ & 10,080 & \\
\hline
\end{tabular}

These results provide detailed guidelines for improving visitors' acceptance of IAS prevention and control. For example, estimates for "ecological shock" and "tour range" are -0.014 and -0.0099 , respectively, showing that visitors are more willing to exchange reduced recreational range for lower ecological shock. Specifically, visitors are willing to sacrifice up to $1.41 \%$ tour range for a $1 \%$ reduction in ecological shock. Therefore, if limiting the tour range could help the NP management carry out IAS prevention and control measures more easily and use methods with less ecological shock, visitors would still support the measures even if their tour range is reduced.

The estimate for "health risk" is -0.0109 , which has a 1-to-1 ratio with "tour range". This result shows that visitors are willing to sacrifice recreational area to reduce the likelihood of health risks. They are willing to sacrifice up to $1.1 \%$ of tour range for a $1 \%$ decline in health risk. Expanding the quarantine area could reduce visitors' contact with materials used for IAS prevention and control and avoid any harms to them. The larger the restricted area, the lower the health risk. From the perspective of visitors, the acceptable scope of quarantine could not be expanded indefinitely or even up to the closure of NP. It all depends on the potential health risk. They are willing to accept at most a 1.1\% reduction in recreational area for a $1 \%$ drop in health risk.

The absolute value of the estimate of "ecological shock" is higher than that of "health risk", showing that visitors are more concerned about the ecological impact of IAS prevention and control than about their own health. The ratio of the two is 1.28, indicating that visitors could accept a higher risk to health, but they are willing to take up to $1.28 \%$ more health risk to reduce $1 \%$ of ecological impact in the face of an IAS prevention and control measure with lower ecological shock.

The estimate of "waiting time" is similar to "health risk". Its ratio (trade-off) with other externalities of IAS prevention and control measures is also similar to that of "health risk", and so is the interpretation of the meaning of the estimates.

\section{Discussion}

The results show that there are negative externalities associated with IAS prevention and control measures, which are unwanted because they reduce the utility of the public. However, though negative externalities are unavoidable, visitors' support of IAS prevention and control measures could still be maximized by adjusting the proportions of various types of negative externalities. 
The conclusion of this research agrees with previous literature that IAS prevention and control is supported by the research results. The study of Rolfe and Windle (2014) on the willingness to pay of residents of Brisbane, Australia for RIFA prevention found a negative ASC, indicating that respondents were prone to choosing IAS prevention and control. That result is similar to our ASC estimate. Adams et al. (2011) studied Florida residents' willingness to pay for accessing state parks and concluded that each visitor was willing to pay an average of $\$ 5.41$ to reduce the coverage of exotic invasive plants. The estimate of biodiversity was positive, which meant that the decline in biodiversity caused by IAS prevention and control would decrease visitors' utility. Their result conforms to our negative estimate of "ecological shock". Our estimate of "tour range" is negative, indicating that limiting visitors' recreational area for IAS prevention would reduce their utility. This result is in line with the conclusion of Beville et al. (2012) that closing recreational fishing areas would lower utility.

This research also proposes several elements that have not been studied by previous research but are more in line with the needs of NPs for the prevention and control of IAS. We obtain visitors' preference for various negative externalities of IAS prevention and control measures and their willingness to pay to avoid those externalities. Based on those results, NPs could analyze whether IAS prevention and control conform to visitors' trade-offs of various negative externalities so that they may choose the plan that maximizes visitors' welfare. Our results are more specific, more in line with the needs of NPs in the actual planning of IAS prevention and control measures and consider the utility of visitors of NPs.

This study finds that respondents prefer IAS prevention and control, low ecological impact and no reduction in tour range. Those findings agree with the conclusions of the studies by Rolfe and Windle (2014), Adams et al. (2011), and Beville et al. (2012). However, this study goes further by exploring the trade-offs of those variables. Specifically, visitors would like to exchange a 1.4\% reduction in tour range for a $1 \%$ decrease in ecological impact. Compared with previous research, these findings better answer the needs of the actual planning of IAS prevention and control. NPs preserve important ecological and cultural landscapes and are popular tourist attractions. However, IAS seriously interrupt the operations and management of NPs and create a unique dilemma. To solve this problem, this paper proposes two approaches, a focus on the externalities of IAS prevention and control and the evaluation of the public's trade-offs of various externalities in IAS prevention and control. The first advocates that the NPs' management must carefully consider the externalities of the prevention and control measures before making any choices. From the perspective of visitors, the second evaluates visitors' trade-offs of various negative externalities associated with the measures, so as to provide a basis for NPs to make decisions and choose the IAS prevention and control measures that have least impact on visitors (maximum utility) and are most supported by visitors.

\section{Conclusions and Policy Suggestions}

This paper uses the choice experiment method to study the preference of visitors of NPs for negative externalities in IAS prevention and control measures and selects visitors to Shei-Pa NP as the research objects. The topic of this research is the negative externalities of IAS prevention and control measures, which have not yet been fully discussed by academia. Moreover, there is scarcely any research on the public preference (trade-off) for those negative externalities. Therefore, the research topic of this paper is highly innovative. Our research uses a stratified random sampling method to decide the time of the onsite questionnaire survey. By combining random selection of the first and the last samples and systematic sampling in the onsite survey, we increase the randomness of respondents' chances of being selected. Because those methods are rarely used, they could serve as a reference for other onsite survey research studies.

The study shows that visitors prefer IAS prevention and control more so than not. They care most about the measures' impact on ecological environment, followed by personal health risk, waiting time and, finally, reduced recreational area. The estimate of ASC tells us whether visitors support IAS prevention and control measures. A negative ASC indicates that the utility of choosing "none of the above" is lower than that of any prevention and control measure. Thus, we could conclude that 
visitors prefer the prevention and control of IAS. In terms of visitors' willingness to pay for negative externalities of IAS prevention and control measures, they are willing to pay 9.3 NTD for a $1 \%$ reduction in ecological shock, 7.3 NTD for a 1\% decrease in health risk, 7.1 NTD for 1 min less waiting time, and 6.6 NTD for a $1 \%$ reduction in tour range. Decreasing any negative externalities of IAS prevention and control measures could improve visitors' welfare. Prevention and control measures that conform to the trade-off relationship between various externalities are those that could maximize visitors' welfare.

This study contributes to both empirical application and academic research. Although it is a case study of Taiwan's Shei-Pa NP, its findings are consistent with previous studies, meaning that the findings of this research are generalizable and can serve as reference for other NPs that are planning IAS prevention and control. Additionally, the methods used in this study, such as trade-off relations between various negative externalities of IAS prevention and control measures, are not seen in previous research but could better address the needs of IAS prevention and control. The onsite random sampling method could provide reference for other studies using onsite surveys to improve the randomness of sampling and the efficiency of statistical analysis.

Although the research objects of this study are Taiwan's Shei-Pa NP and its visitors, its findings could provide reference for other areas that are under IAS prevention and control. Attributes used in this study are not unique or exclusive to the Taiwan Shei-Pa NP. Instead, they are collected and summarized from case studies and research findings around the world. They are common in various settings of daily life, such as parks, green spaces, campuses, lakes and streams in many countries. When taking IAS prevention and control measures in those living areas, at least one or even several attributes discussed in this paper would be involved. Of course, the estimates and trade-off relations should vary with cultural, social, economic, environmental differences in various countries and the characteristics of areas under prevention and control, but there are no obvious differences in the types of attributes. While carrying out IAS prevention and control, these areas could use the attributes in this paper to estimate the parameters or borrow the estimates of this paper to evaluate the IAS prevention and control measures that cause the least negative externalities to the public, so as to gain public support for IAS prevention and control measures. Major contributions of this paper to the research and practice of ecological conservation are summarizing the negative externalities of IAS prevention and control measures; putting forward an empirical approach to evaluate the public's willingness to pay for IAS prevention and control measures and for negative externalities of the measures; exploring the public's trade-offs of various negative externalities of IAS prevention and control measures; and proposing to reduce the impact of negative externalities on the public by adjusting the combination of those externalities, so as to improve public support for IAS policy and sustainability of NPs.

Author Contributions: Conceptualization, T.-M.L. and C.-M.T.; Methodology, T.-M.L.; Software, T.-M.L.; Validation, T.-M.L. and C.-M.T.; Formal Analysis, T.-M.L.; Investigation, C.-M.T.; Resources, T.-M.L.; Data Curation, C.-M.T.; Writing-Original Draft Preparation, C.-M.T.; Writing—Review \& Editing, T.-M.L.; Visualization, C.-M.T.; Supervision, T.-M.L.; Project Administration, T.-M.L.; Funding Acquisition, T.-M.L.

Funding: This research was funded by Ministry of Science and Technology, Taiwan, grant number NSC 101-2621-M-002-032, NSC 102-2621-M-002-027, Most 103-2621-M-002-019, and Most 105-2119-M-110-012.

Conflicts of Interest: The authors declare that they have no conflict of interest.

\section{References}

1. Eagles, P.F.; McCool, S.F.; Haynes, C.D.; Phillips, A. Sustainable Tourism in Protected Areas: Guidelines for Planning and Management; IUCN Gland: Gland, Switzerland, 2002; Volume 8.

2. Mount, A.; Pickering, C.M. Testing the capacity of clothing to act as a vector for non-native seed in protected areas. J. Environ. Manag. 2009, 91, 168-179. [CrossRef]

3. Perrings, C. Mitigation and adaptation strategies for the control of biological invasions. Ecol. Econ. 2005, 52, 315-325. [CrossRef]

4. Liu, T.-M.; Yang, W.-C. Using choice experiments to inform management of black-faced spoonbill reserve in Taiwan. Cogent Soc. Sci. 2019, 5, 1611984. [CrossRef] 
5. Balmford, A.; Green, J.M.; Anderson, M.; Beresford, J.; Huang, C.; Naidoo, R.; Walpole, M.; Manica, A. Walk on the wild side: Estimating the global magnitude of visits to protected areas. PLoS Biol. 2015, 13, e1002074. [CrossRef]

6. Liu, T.-M. Testing on-site sampling correction in discrete choice experiments. Tour. Manag. 2017, 60, $439-441$. [CrossRef]

7. Lee, C.E. Evolutionary genetics of invasive species. Trends Ecol. Evol. 2002, 17, 386-391. [CrossRef]

8. Thomas, M.B.; Reid, A.M. Are exotic natural enemies an effective way of controlling invasive plants? Trends Ecol. Evol. 2007, 22, 447-453. [CrossRef]

9. Boon, P.I.; Fluker, M.; Wilson, N. A ten-year study of the effectiveness of an educative programme in ensuring the ecological sustainability of recreational activities in the Brisbane Ranges National Park, South-eastern Australia. J. Sustain. Tour. 2008, 16, 681-697. [CrossRef]

10. Shrestha, B.K.; Dangol, D.R. Impact of Mikania micrantha HBK invasion on diversity and abundance of plant species of Chitwan National Park, Nepal. J. Inst. Sci. Technol. 2014, 19, 30-36. [CrossRef]

11. Dove, C.J.; Snow, R.W.; Rochford, M.R.; Mazzotti, F.J. Birds consumed by the invasive Burmese python (Python molurus bivittatus) in Everglades National Park, Florida, USA. Wilson J. Ornithol. 2011, 123, $126-131$. [CrossRef]

12. Walker, L.R.; Vitousek, P.M. An invader alters germination and growth of native dominant tree in Hawai'i. Ecology 1991, 72, 1449-1455. [CrossRef]

13. Lenz, L.; Taylor, J.A. The influence of an invasive tree species (Myrica faya) on the abundance of an alien insect (Sophonia rufofascia) in Hawai'i Volcanoes National Park. Biol. Conserv. 2001, 102, 301-307. [CrossRef]

14. Mukwada, G.; Chingombe, W.; Taru, P. Strifes of the frontier: An assessment of Acacia mearnsii related park-community conflicts in the Golden Gate Highlands National Park, South Africa. J. Integr. Environ. Sci. 2016, 13, 37-54. [CrossRef]

15. Salinas, R.A.; Stiver, W.H.; Corn, J.L.; Lenhart, S.; Collins, C.; Madden, M.; Vercauteren, K.C.; Schmit, B.B.; Kasari, E.; ODOI, A.; et al. An individual-based model for feral hogs in Great Smoky Mountains National Park. Nat. Resour. Model. 2015, 28, 18-36. [CrossRef]

16. Catford, J.; Lindenmayer, D.; Hobbs, R. Non-target impacts of weed control on birds, mammals and reptiles. Ecosphere 2017. [CrossRef]

17. Alston, D.G.; Tepedino, V.J.; Bradley, B.A.; Toler, T.R.; Griswold, T.L.; Messinger, S.M. Effects of the insecticide phosmet on solitary bee foraging and nesting in orchards of Capitol Reef National Park, Utah. Environ. Entomol. 2007, 36, 811-816. [CrossRef] [PubMed]

18. Bower, D.S.; Valentine, L.E.; Grice, A.C.; Hodgson, L.; Schwarzkopf, L. A trade-off in conservation: Weed management decreases the abundance of common reptile and frog species while restoring an invaded floodplain. Biol. Conserv. 2014, 179, 123-128. [CrossRef]

19. Stark, J.D.; Chen, X.D.; Johnson, C.S. Effects of herbicides on Behr's metalmark butterfly, a surrogate species for the endangered butterfly, Lange's metalmark. Environ. Pollut. 2012, 164, 24-27. [CrossRef]

20. Lonsdale, W.; Lane, A. Tourist vehicles as vectors of weed seeds in Kakadu National Park, Northern Australia. Biol. Conserv. 1994, 69, 277-283. [CrossRef]

21. Whinam, J.; Chilcott, N.; Bergstrom, D. Subantarctic hitchhikers: Expeditioners as vectors for the introduction of alien organisms. Biol. Conserv. 2005, 121, 207-219. [CrossRef]

22. Corona, P.; Chirici, G.; McRoberts, R.E.; Winter, S.; Barbati, A. Contribution of large-scale forest inventories to biodiversity assessment and monitoring. For. Ecol. Manag. 2011, 262, 2061-2069. [CrossRef]

23. Ip, K.K.; Liang, Y.; Lin, L.; Wu, H.; Xue, J.; Qiu, J.-W. Biological control of invasive apple snails by two species of carp: Effects on non-target species matter. Biol. Control 2014, 71, 16-22. [CrossRef]

24. Clark, S.G.; Vernon, M.E. Governance challenges in joint inter-jurisdictional management: The Grand Teton National Park, Wyoming, elk case. Environ. Manag. 2015, 56, 286-299. [CrossRef]

25. Saayman, M.; Martín, J.C.; Román, C. There is no fuzziness when it comes to measuring service quality in national parks. Tour. Econ. 2016, 22, 1207-1224. [CrossRef]

26. Ryan, M.; Gerard, K.; Amaya-Amaya, M. Using Discrete Choice Experiments to Value Health and Health Care; Springer Science \& Business Media: Berlin, Germany, 2007; Volume 11.

27. Gundersen, V.; Mehmetoglu, M.; Vistad, O.I.; Andersen, O. Linking visitor motivation with attitude towards management restrictions on use in a national park. J. Outdoor Recreat. Tour. 2015, 9, 77-86. [CrossRef] 
28. Zhang, H.; Zhang, J.; Kuwano, M. An integrated model of tourists' time use and expenditure behaviour with self-selection based on a fully nested Archimedean copula function. Tour. Manag. 2012, 33, 1562-1573. [CrossRef]

29. LeDoux, C.B.; Martin, D.K. Proposed BMPs for Invasive Plant Mitigation during Timber Harvesting Operations; USDA Forest Service: Washington, DC, USA, 2013.

30. Adams, D.C.; Bwenge, A.N.; Lee, D.J.; Larkin, S.L.; Alavalapati, J.R. Public preferences for controlling upland invasive plants in state parks: Application of a choice model. For. Policy Econ. 2011, 13, 465-472. [CrossRef]

31. Hanley, N.; Mourato, S.; Wright, R.E. Choice modelling approaches: A superior alternative for environmental valuatioin? J. Econ. Surv. 2001, 15, 435-462. [CrossRef]

32. Hoyos, D. The state of the art of environmental valuation with discrete choice experiments. Ecol. Econ. 2010, 69, 1595-1603. [CrossRef]

(C) 2019 by the authors. Licensee MDPI, Basel, Switzerland. This article is an open access article distributed under the terms and conditions of the Creative Commons Attribution (CC BY) license (http://creativecommons.org/licenses/by/4.0/). 